Jurnal Geografi, Edukasi dan Lingkungan (JGEL) Vol. 5, No. 1, Januari 2021:1-14

P-ISSN: 2579-8499; E-ISSN: 2579-8510

Doi: https://doi.org/10.22236/jgel.v5i1.6068

Website: http://journal.uhamka.ac.id/index.php/jgel

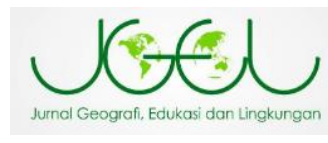

\title{
Field Study Terintegrasi Hybrid Learning: Solusi Pembelajaran Dasar-Dasar Geologi Selama Pandemi Covid-19
}

\author{
Dwi Angga Oktavianto* \\ SMK Negeri 1 Binuang, Kabupaten Tapin, Provinsi Kalimantan Selatan, Indonesia \\ *E-mail: oktavianto.angga7@ gmail.com \\ Received: 15122020 / Accepted: 0401 2021/ Published online: 29012021
}

\begin{abstract}
ABSTRAK
Pandemi COVID-19 memaksa dunia pendidikan untuk segera berbenah. Hal ini berlaku dalam proses pembelajaran, berubah dari mode tatap muka menuju mode pembelajaran daring. Penelitian ini bertujuan untuk memanfaatkan aktivitas pembelajaran field study terintegrasi hybrid learning dalam pembelajaran DasarDasar Geologi, dan apakah pembelajaran tersebut dapat meningkatkan hasil belajar siswa. Desain Penelitian Tindakan Kelas (PTK) digunakan dalam penelitian ini. Subjek pada penelitian ialah Kelas X SMK Negeri 1 Binuang pada Program Keahlian Geologi Pertambangan Tahun Pelajaran 2019/2020 dengan jumlah 32 siswa. Analisis data PTK menggunakan analisis deskriptif kuantitatif, yang dilakukan dengan menelaah data hasil belajar sebelum dan setelah siklus, kemudian dilakukan sintesis dengan kajian pustaka. Hasil penelitian menunjukkan Siklus II menghasilkan angka 77,78\% siswa tuntas Kriteria Ketuntasan Minimal (KKM) atau turun dari Siklus pertama 84,374\%. Saat Pra Siklus menunjukkan jumlah siswa tuntas KKM hanya 18,75\%. Hasil yang diperoleh dalam PTK ini menandakan bahwa field study terintegrasi hybrid learning berpotensi untuk menjadi model pembelajaran Dasar-Dasar Geologi di masa Pandemi COVID-19.

Kata Kunci: Field study, Hybrid Learning, Geologi Dasar
\end{abstract}

\section{ABSTRACT}

The COVID-19 pandemic is forcing the world of education to immediately improve. This applies in the learning process, changing from face-to-face to online learning mode. This study aims to take advantage of integrated hybrid learning field study activities in learning the Basics of Geology, and whether this learning can improve student learning outcomes. Classroom Action Research (CAR) was used in this study. The subjects in the study were Class X SMK Negeri 1 Binuang in the Mining Geology Expertise Program for the 2019/2020 academic year with a total of 32 students. The CAR data analysis used quantitative descriptive analysis, which was carried out by examining the learning outcome data before and after the cycle, then synthesizing it with literature review. The results of the study in Cycle II showed that $77.78 \%$ of students had completed the Minimum Completion Criteria (KKM) or decreased from the first cycle of $84.374 \%$. The pre-cycle shows that the number of students completing the KKM is only $18.75 \%$. The results obtained in this CAR indicate that the integrated hybrid learning field study has the potential to become a learning model for the Basics of Geology during the COVID-19 Pandemic.

Keywords: Field study, Hybrid Learning, Basics of Geology 


\section{PENDAHULUAN}

Pandemi COVID-19 memaksa dunia untuk menuju new normal. Dunia pendidikan, dalam hal ini proses pembelajaran di sekolah juga harus berubah (Reimers et al., 2020). Tantangan besar bagi guru adalah tetap menghadirkan pembelajaran berkualitas. Sebagai garda terdepan dalam mempersiapkan, melaksanakan, dan mengevaluasi pembelajaran guru harus selalu inovatif dan kreatif. Salah satu cara yang banyak ditempuh ialah melalui pembelajaran online.

Pembelajaran online menjadi kebiasaan baru yang musti dilaksanakan. Transisi dari belajar secara tradisional menuju belajar online akibat pandemi COVID-19 memiliki potensi untuk berhasil. Menyiapkan pembelajaran dan menilai dengan format baru akibat pandemi COVID-19 perlu disusun secara seksama agar pembelajaran berhasil (Basilaia \& Kvavadze, 2020). Sebagai contoh, ulangan dalam mode open book yang selama pembelajaran face-to-face (tatap muka) tidak populer, namun selama pembelajaran online akan menjadi kebiasaan baru yang harus diperhatikan oleh guru. Selain tidak meratanya sinyal internet, tentu banyak tantangan dan kendala untuk menghadirkan pembelajaran online yang berkualitas.

Permasalahan pembelajaran online tidak hanya pada penyusunan rencana dan penilaian pembelajaran. Siswa sering bermasalah dengan kedisiplinan, keterbatasan penguasaan materi, dan lingkungan (rumah) yang tidak kondusif selama belajar online (Bao, 2020). Berbagai permasalahan yang ada menjadi variabel dalam menentukan sukses atau tidaknya pembelajaran selama pandemi COVID-19. Berbagai permasalahan tersebut seharusnya bukanlah menjadi kendala, seperti kebijakan yang diambil pemerintah China "Suspending Classes Without Stopping Learning" (Zhang et al., 2020), pemerintah Indonesia juga mengambil kebijakan serupa. Guru harus berusaha untuk tetap merencanakan, melaksanakan, dan menilai pembelajaran sebaik mungkin. Sekolah meskipun belum dibuka, tetapi pembelajaran harus tetap berlangsung diberbagai jenjang persekolahan.

Pembelajaran online memiliki kelemahan. Persepsi negatif siswa terhadap pembelajaran online menimbulkan ketidak berhasilan dalam belajar (Todhunter, 2013). Hasil pembelajaran online merupakan wujud dari budaya yang bersumber dari kebiasaan (Liu et al., 2010). Budaya belajar diwujud oleh karakter siswa pembelajar, penguasaan teknologi, dan kemandirian belajar (Wang et al., 2013). Ketiga hal tersebut berdampak pada hasil belajar secara online. Kesiapaan belajar online atau Online Learning Readiness Scale (OLRS) dipengaruhi oleh selfdirected learning, motivation for learning, computer/Internet self-efficacy, learner control, and online communication selfefficacy (Hung et al., 2010). Banyak dimensi yang perlu diperhatikan dalam pembelajaran online agar pembelajaran berhasil mencapai tujuan.

Sekolah kejuruan (vokasi) menghadapi tantangan yang berbeda dari sekolah umum. Program keahlian geologi pertambangan menjadi salah satu dari sekolah vokasi yang menghadapi dilema pembelajaran di masa pandemi. Geologi merupakan pembelajaran teknik yang harus dilakukan secara hands-on (Schifman et al., 2013). Sebagai pembelajaran hands-on tentunya belajar geologi tidak bisa hanya sekedar belajar 
online di depan laptop atau smartphone. Pembelajaran vokasi dengan online memiliki banyak keterbatasan dibading pembelajaran face-to-face (Sahin, 2010). Perlu dirancang pembelajaran yang tidak hanya sekedar online, tetapi juga tetap memperhatikan aspek keterampilan yang perlu dikuasai siswa seperti halnya belajar secara hands-on. Namun karena ada pandemi, hands-on harus tetap dikombinasikan dengan pembelajaran online.

Hybrid Learning dipilih sebagai sistem pembelajaran yang diaplikasikan pada mata pelajaran Dasar-Dasar Geologi. Hal ini didasari alasan bahwa Hybrid Learning mampu mengkombinasikan pembelajaran tatap muka dan pembelajaran online pada pendidikan vokasi (Sahin, 2010). Hybrid Learning mempunyai potensi untuk menggabungkan keduanya (Samson \& Samson, 2020). Hybrid mendapatkan keunggulan dari pembelajaran online dan memadukannya dengan keunggulan dari pembelajaran tatap muka (Clark \& James, 2012). Geologi mempunyai kemiripan dengan geografi (Stokes et al., 2011), dan banyak penelitian yang menyatakan bahwa Hybrid Learning mempunyai keberhasialan dalam pembelajaran geografi (Dikmenli, 2013) dalam (Godlewska et al., 2019; McPhee \& Pickren, 2017; Mitchell \& Forer, 2010; Moore \& Gilmartin, 2010). Namun penelitian-penelitian yang telah dilakukan belum membahas mengenai pembelajaran lapangan (praktik di luar kelas) dikombinasikan dengan Hybrid Learning. Pembelajaran praktik di luar kelas dapat berupa field study, outdoor study, atau fieldwork.

Pembelajaran geologi bercorak Field study. Field study merupakan kegiatan esensial dalam pembelajaran geologi dan geografi (Stokes et al., 2011). Sebagai sesuatu yang esensial Field study wajib dilakukan, terlebih materi-materi yang memang harus ke lapangan seperti mengukur struktur singkapan dan deskripsi batuan (Pringle et al., 2004). Field study merupakan sumber pengetahuan bagi siswa yang belajar geologi (Barros et al., 2012). Field study menjembatani pemahaman siswa secara teoritis dengan kenyataan di alam atau dunia nyata (France \& Haigh, 2018). Field study hendaknya digunakan dalam intensitas yang tinggi untuk belajar geologi atapun geografi fisik. Guru perlu menyusun tahapan Field study sesuai dengan teori dan keadaan di lapangan.

Ada banyak model Field study. Setidaknya ada tujuh model Field study dalam belajar ilmu kebumian (France \& Haigh, 2018). Model-model Field study tersebut yaitu; Model "teachercentered"; Model "the field as laboratory"; Model "project-oriented; Model "curriculum centered"; Model "technologically-enhanced"; Model "research-apprenticenship"; dan Model "reflective international Field study" (France \& Haigh, 2018). Sepanjang yang peneliti baca, belum pernah ada model yang mengintegrasikan Fieldstudy dengan Hybrid Learning. Memasukkan Field study dalam Hybrid Learning merupakan tantangan dalam hal perencanaannya, pelaksanaannya di kelas dan lapangan, serta bagaimana penilaian pembelajaran geologi semacam ini.

Field study yang baik diterapkan dengan pendekatan saintifik. Pendekatan semacam ini memerlukan sintak-sintak yang dalam praktiknya harus sistematis mulai dari melakukan pengamatan; kemudian menyusun pertanyaan; dilanjutkan dengan mengumpulkan informasi; selanjutnya mengasosiasikan 
informasi-informasi yang didapat dan diakhiri dengan mengkomunikasikan (Oktavianto, 2019). Bentuk dari mengkomunikasikan dalam Field study dapat berupa produk (Oktavianto et al., 2017). Produk dari deskripsi batuan ialah lembar deskripsi batuan (Pringle et al., 2004) dalam (Schifman et al., 2013). Siswa lebih menyukai penilaian dalam bentuk produk atau proyek dibandingkan penilaian mengerjakan soal (Oktavianto, 2019). Pembelajaran Field study terintegrasi blended menggunakan lembar deskripsi batuan berupa Google Form yang harus diisi oleh siswa.

Integrasi Field study dengan Hybrid Learning memiliki potensi untuk menghadirkan pembelajaran berkualitas. Field study dapat membekali siswa kemampuan memecahkan masalah, berpikir kritis, kerja sama tim dan kecerdasan emosional (France \& Haigh, 2018). Sebelum mengintegrasikan antara Hybrid Learning dan Fieldstudy perlu dipahami karakteristik materi-materi pelajaran yang ada. Materi yang dapat diajarkan secara blended pada mata pelajaran dasar Dasar-Dasar Geologi antara lain batuan (Schifman et al., 2013), struktur geologi singkapan (Pringle et al., 2004), dan bentang alam hasil gaya geologi (Oktavianto, 2019). Materi dalam Dasar-Dasar Geologi yang harus dilakukan dengan Field study diantaranya juga yang telah disebutkan tersebut. Jadi ketiga materi yang telah disebutkan, berpotensi untuk dilaksanakan dalam pembelajaran Field study terintegrasi Hybrid Learning.

$$
\text { Tantangan lain dalam }
$$
pembelajaran Field study terintegrasi Hybrid Learning ialah kewajiban melaksanakan kegiatan sesuai ketentuan protokol kesehatan. Penggunaan masker, jaga jarak, dan menghindari kerumunan merupakan hal umum dalam protokol kesehatan yang harus dilakukan selama pembelajaran. Peralatan yang digunakan seperti lup, cairan $\mathrm{HCl}$, dan lain-lain setiap siswa diusahakan untuk memiliki. Namun penggunaan palu geologi dan kompas geologi biasanya difasilitasi sekolah mengingat harganya mahal. Jadi selama pembelajaran di masa pandemi ini, palu yang digunakan siswa ialah palu biasa untuk memukul paku, sedangkan kompas geologinya menggunakan kompas geologi mode aplikasi bernama Geological Compass yang tersedia di Playstore.

Bersumber dari latar belakang yang ada, maka tersusunlah bentuk rumusan penelitian berupa; 1) Bagaimana pembelajaran Field study terintegrasi Hybrid Learning dalam mata pelajaran dasar-dasar geologi selama pandemi COVID-19?; dan 2) Apakah pembelajaran Field study terintegrasi Hybrid Learning dapat efektif digunakan dalam mata pelajaran dasar-dasar geologi selama pandemi COVID-19?

\section{METODE PENELITIAN}

Desain Penelitian Tindakan Kelas (PTK) menjadi metode dalam penelitian ini. PTK dipilih karena peneliti ingin menjawab rumusan masalah dengan mendalam, terkait perencanaan, pelaksanaan, dan penilian pembelajaran. Disamping hal tersebut, PTK juga dapat mengetahui efektifitas dari tindakan yang diterapkan. Adapun gambar siklus PTK disajikan pada Gambar 1: 


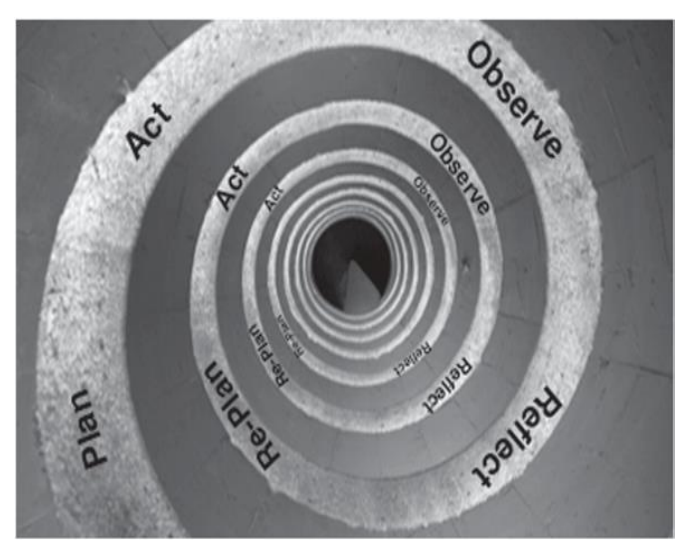

Gambar 1. Siklus PTK

Sumber: (Kemmis, S. McTaggart, R. \& Nixon, 2014)

\section{Waktu dan Lokasi Penelitian}

Penelitian Tindakan Kelas (PTK) ini dilakukan di Kelas $\mathrm{X}$ Geologi Pertambangan SMK Negeri 1 Binuang dengan jumlah siswa 32 orang. Mata pelajaran yang dipelajari dalam PTK ini ialah Dasar-Dasar Geologi dengan materi batuan. PTK dilakukan selama 1 (satu) pra siklus dan 2 (dua) siklus tindakan pada Bulan Mei 2020. Pembagian materi setiap siklus ialah; pra siklus dengan sub materi batuan beku, siklus I sub materi batuan sedimen, dan siklus II mengenai batuan metamorf. Tingkat keberhasilan PTK jika 75\% siswa tuntas KKM (Gambar 2).

\section{Alat dan Bahan}

Peralatan yang disiapkan dalam pembelajaran berupa peralatan geologi lapangan yaitu: Lup, $\mathrm{HCl}$, dan meteran yang disediakan oleh masing-masing siswa. Palu geologi diganti dengan palu yang ada di rumah masing-masing siswa atau alat lain yang dapat dihgunakan untuk mengambil sampel batuan. Kompas Geologi Bruton diganti Kompas Geologi berupa aplikasi yang siswa diwajibkan untuk mengunduh di Playstore. Komparator besar butir menggunakan milik masing-masing siswa yang memang wajib di miliki oleh siswa Geologi Pertambangan.

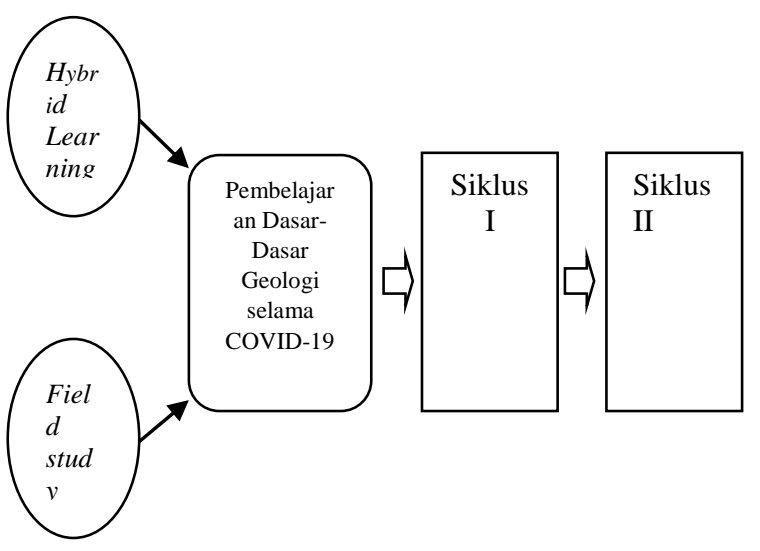

Gambar 2. Riset Framework

\section{Jenis Penelitian}

Penelitian ini merupakan Penelitian Tindakan Kelas (PTK). PTK ini dilakukan melalui dua siklus.

\section{Analisa Data}

Adapun setiap siklusnya (siklus I dan II) dilakukan dalam empat tahap sesuai dengan Gambar 1. Mulai dari perencanaan (Plan) di awal, dilanjutkan dengan adanya tindakan (Act), disertai observasi (Observe); dan kemudian diakhiri dengan refleksi (Reflect). Perencanaan digunakan untuk menyusun Rencana Pelaksanaan Pembelajaran (RPP) dengan format sesuai Surat Edaran Kementerian Pendidikan dan Kebudayaan (Kemendikbud) Nomor 14 Tahun 2019 tentang penyederhanaan RPP. RPP pada Siklus I menggunakan Fieldstudy terintegrasi Hybrid Learning. Sistem pembelajaran dilakukan dengan memanfaatkan Google Classroom. Bahan ajar berupa video deskripsi batuan, pengukuran struktur geologi batuan, dan materi berupa PDF dari guru dimasukkan pada Google Classroom. Penilaian menggunakan rubrik penilaian berbasis produk lembar deskripsi batuan, yang 
harus siswa isi dan unggah pada Google Form.

Tahap tindakan dilakukan setelah perencaaan selesai disusun. Tahap ini digunakan untuk menerapkan treatment (tindakan) berupa Field study terintegrasi Hybrid Learning. Langkah-langkah Field study dilakukan mandiri oleh masingmasing siswa, namun di izinkan adanya kerja sama dalam mengunjungi tempat yang terdapat singkapan batuan. Jadwal disusun secara bergiliran dengan memperhatikan tidak terjadi kumpulan siswa dalam jumlah yang banyak. Selanjutnya, siswa secara mandiri melakukan deskripsi batuan di rumah masing-masing, hasil deskripsi batuan diisikan pada Google Form yang linknya sudah guru bagikan.

Tahap observasi dilakukan dengan cara guru mengecek apakah siswa benarbenar mengunjungi lokasi yang sudah ditentukan, dan bagaimana siswa mengambil sampel batuan dilakukan dengan cara melihat foto yang siswa kirim melalui WhatsApp (WA). Dalam tahap ini guru perlu berinteraksi secara online dengan siswa, agar setiap aktivitas yang dilakukan siswa dapat dimati oleh guru dan mendapatkan umpan balik dari guru.

Tahap refleksi dilakukan oleh guru mulai dari menilai produk hasil deskripsi batuan yang diunggah oleh siswa, kemudian membuat persentase siswa yang tuntas KKM, dan mengidentifikasi tingkat keberhasilan pembelajaran. Setelah itu dilakukan sintesis dan analisis dari hasil yang didapat dengan kajian pustaka. Hasil yang didapat sudah menunjukkan keberhasilan, sehingga pada siklus II dalam tahap perencanaan kembali digunakan perencanaan awal dengan mengganti lembar deskripsi batuan sedimen menjadi lembar deskripsi batuan metamorf. Selanjutnya dilakukan tahap tindakan, observasi dan refleksi siklus II.

\section{HASIL DAN PEMBAHASAN Pra Siklus}

Pembelajaran pra siklus dilakukan sebelum adanya tindakan. Pembelajaran pra siklus dilaksanakan dalam merespon adanya intrusksi dan edaran bahwa pembelajaran dilakukan secara online. Pembelajaran online pada mata pelajaran Dasar-Dasar Geologi dilakukan dalam mode dalam jaringan (daring) dengan memanfaatkan Google Classroom. Guru mengunggah semua materi tentang sub materi batuan beku. Sedangkan diskusi dan tanya jawab dilakukan dengan WA, ini mempertimbangkan aksesibilitas dan kebiasaan siswa. Siswa masih belum terbiasa menggunakan Google Classroom, namun sudah sangat familiar dengan WA.

Penilaian dilakukan dengan Google Assesment. Penilaian semacam ini juga merupakan hal baru yang pernah dilakukan oleh siswa. Sebelumnya siswa pernah menggunakan penilaian mode daring dengan aplikasi lain, namun dalam bentuk pilihan ganda. Pengalaman siswa menghadapi ujian daring diperoleh saat melaksanakan Penilaian Akhir Semester (PAS) 1. SMK Negeri 1 Binuang telah melaksanakan PAS secara daring sejak beberapa tahun terakhir. Sedangkan dalam pembelajaran kali ini siswa melakukannya dalam bentuk soal uraian dan jawab singkat dengan format Lembar Deskripsi Batuan. Adapun persentase siswa yang mencapai KKM dalam pembelajaran batuan beku dapat diamati melalui Gambar 3.

Pada Gambar 3. menunjukkan bahwa pembelajaran online yang dilakukan belum efektif. Siswa yang memperoleh nilai Kriteria Ketuntasan 
Minimal (KKM) hanya berjumlah 6, atau $18,75 \%$ dari 32 siswa Kelas X Geologi Pertambangan. Hal ini artinya tidak sampai seperempat siswa yang tuntas KKM. Padahal dalam pembelajaran online, siswa dapat mengerjakan soal secara open book. Hal ini juga menjadi perhatian khusus oleh guru selaku peneliti, apakah materi yang telah diberikan guru melalui Google Classroom tidak dibaca oleh siswa? Apakah siswa hanya masuk ke Google Classroom untuk melakukan presensi kehadiran saja tanpa memperdulikan materi? Pertanyaanpertanyaan semacam itu juga dapat mengidentifikasi bahwa kemauan anak untuk membaca (literasi) rendah. Pra siklus ini belum memperhatikan kesiapaan belajar online atau OLRS yang dipengaruhi oleh kemampuan belajar, motivasi untuk belajar, penguasaan internet dan komputer, kontrol diri siswa, dan kemampuan komunikasi daring (Hung et al., 2010).

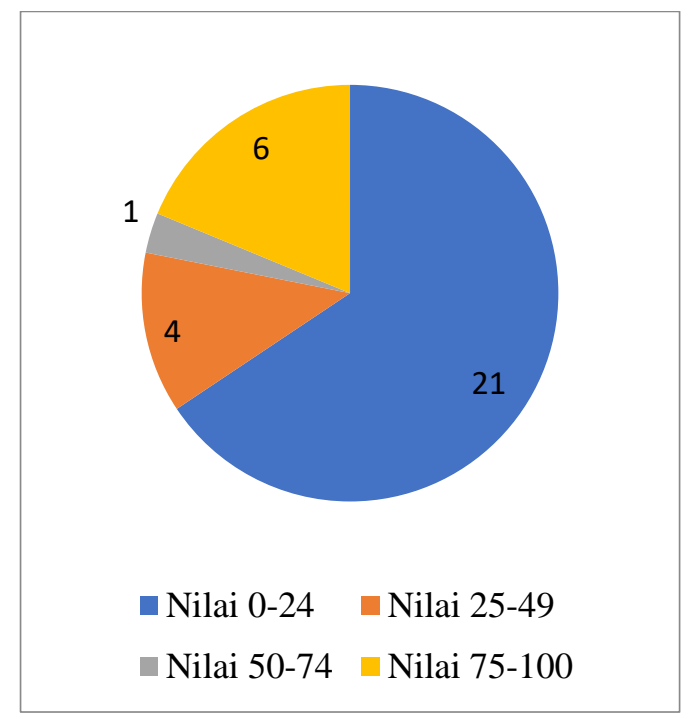

Gambar 3. Diagram Nilai Yang Diperoleh Saat Pra Siklus

Siswa banyak yang cenderung pasif selama interaksi di WA grup. Pertanyaan atau pernyataan yang sering disampaikan siswa kepada guru berupa;
"Pak, Saya sudah masuk di Google Classroom." atau "Pak saya, apakah sudah di masukkan di absensi kehadiran?" Hal seperti ini memberi gambaran bahwa dalam pembelajaran online, anak hanya sekedar hadir dan minim terlibat aktif dalam pembelajaran. Berbeda saat pembelajaran tatap muka, siswa terlihat aktif membaca. Ini bisa jadi karena persepsi siswa terhadap pembelajaran online (Todhunter, 2013). Kasus seperti ini juga mencerminkan kemandirian siswa dalam belajar rendah (Wang et al., 2013). Temuan ini sesuai dengan yang disampaikan oleh kedisiplinan, keterbatasan penguasaan materi, dan lingkungan (rumah) yang tidak kondusif selama belajar online mempengaruhi hasil belajar siswa. Siswa diminta membaca materi dalam bentuk PDF, memperhatikan video cara pendeskripsian batuan namun mereka tidak melakukannya, inilah bentuk rendahnya kedisiplinan. Siswa banyak yang tidak tuntas KKM menunjukkan keterbatasan penguasaa materi. Berbagai permasalahan ini juga dapat dipengaruhi oleh kondisi lingkungan (rumah) yang tidak kondusif, dan hal tersebut di luar kendali dari guru. Hal ini juga dipengaruhi karena guru tidak memperhatikan kesiapaan belajar online atau OLRS.

Temuan dalam pra siklus juga mengindikasikan bahwa siswa di sekolah vokasi tidak bisa belajar dengan baik jika hanya dilakukan pembelajaran online. Ini mengkonfirmasi hasil penelitian Sahin, (2010) yang menyatakan bahwa pembelajaran vokasi secara online memiliki banyak keterbatasan dibanding pembelajaran face-to-face. Selain itu, temuan pada pra siklus ini juga menguatkan geologi merupakan pembelajaran teknik yang harus dilakukan secara hands-on (Schifman et al., 2013). 
Tanpa pembelajaran hands-on, siswa sekolah vokasi Geologi Pertambangan tidak akan menemukan pembelajaran bermakna. Belum berhasilnya pembelajaran online pada mata pelajaran Dasar-Dasar Geologi kemudian akan menjadi dasar perbaikan perencanaan untuk pembelajaran, pelaksanaan pembelajaran selama penelitian, dan dalam melakukan penilaian pada pembelajaran berikutnya.

\section{Siklus I}

\section{Perencanaan}

Perencanaan yang dibuat untuk Siklus I ini ialah hasil dari refleksi pembelajaran yang ditemukan adanya beberapa hambatan selama Pra Siklus. Berbagai kendala dalam pembelajaran online saat Pra Siklus memberikan keyakinan bahwa siswa Geologi Pertambangan harus belajar dengan model lain, yakni Field study terintegrasi Hybrid Learning. Wujud dari perencanaan tertuang dalam RPP Siklus I. Rencana Pelaksanaan Pembelajaran ini berisi langkah-langkah pembelajaran Field study terintegrasi Hybrid Learning. Lembar deskripsi batuan di Google Form pun harus berupa foto batuan yang diambil langsung di lapangan, bukan sekedar gambar batuan yang diambil dari internet. Upaya penggunaan Fieldstudy agar siswa belajar secara hands-on benarbenar diperhatikan pada tahap perencanaan Siklus 1 ini.

\section{Tindakan}

Langkah pada tahap ini berupa; Pertama, siswa menuju lapangan (lokasi singkapan) batuan sedimen yang telah ditentukan oleh guru (berdasarkan jadwal yang disusun agar tidak terjadi kerumunan). Kedua, siswa kemudian merumuskan pertanyaan tentang deskripsi batuan yang mereka ambil di lapangan. Ketiga, siswa mengumpulkan informasi tentang batuan yang didapat. Keempat, siswa melakukan sintesis data dan informasi. Pada langkah keempat ini, ada sintesis informasi dan analisis informasi yang harus dikerjakan di lapangan seperti pengukuran strike dan dip, serta tebal lapisan batuan, tetapi juga ada yang dikerjakan di rumah seperti mengidentifikasi sampel batuan dengan lup, dan memberi $\mathrm{HCl}$ pada batuan untuk mengetahui sampel batuan berbuih atau tidak. Kelima, siswa mengkomunikasikan hasil deskripsinya melalui Google Form lembar deskripsi batuan dan dikirim (submit) ke guru.

\section{Observasi}

Observasi dilakukan melalui foto yang dikirim oleh siswa. Data observasi menunjukkan beberapa siswa tidak memakai sepatu safety dan helm safety (sesuai ketentuan Kesehatan dan Keselamatan Kerja yang selalu disampaikan guru geologi pertambangan ketika akan ke lapangan). Dalam masa pandemi ini, siswa juga masih banyak yang tidak memakai masker saat ke lapangan. Sisi lain menunjukkan bahwa siswa menikmati belajar di lapangan secara hands-on. Hasil deskripsi batuan yang dikirim pun juga baik. Selanjutnya penilaian deskripsi batuan menunjukkan hasil pada Gambar 5.

Siswa masih kesulitan menggunakan Geological Compass yang berupa aplikasi. Siswa lebih menyukai Kompas Geologi Bruton yang biasa mereka gunakan. Masih ditemukan siswa yang tidak hadir dalam pembelajaran, sehingga diberi nilai 0 oleh guru. Selain itu, terdapat siswa yang tidak ke lapangan karena tidak mengirim foto selfie di lapangan. Akan tetapi, mengirim lembar deskripsi batuan dari Google Form, 
sehingga diberi nilai 25. Siswa yang tidak memakai Alat Pelindung Diri (APD), yakni helm dan sepatu safety diberi nilai kurang dari 75.

Penjadwalan yang dilakukan dalam tempo sehari sepertinya memberatkan siswa. Lokasi Field study sudah diusahkan yang paling dekat dengan tempat tinggal siswa, namun masih ada siswa yang tersesat menuju ke lokasi sehingga telat mengumpul tugas. Lokasi pengambilan sampel batuan (singkapan) yang dipilih merupakan daerah yang dapat memperoleh sinyal internet, sehingga guru memiliki kesempatan membimbing siswa. Namun ada lokasi yang tidak bisa digunakan untuk video call, ini yang menjadi temuan sulit untu memberi arahan kepada siswa.

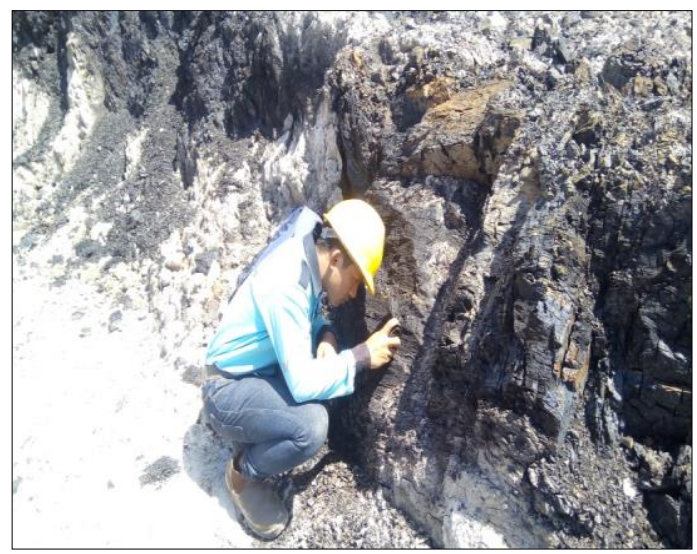

Gambar 4. Mengukur Strike dan Dip dengan Aplikasi Geological Comppass

Sebagian besar siswa pada Siklus I melaksanakan pembelajaran dan penilaian dengan baik. Hal ini dapat diamati dari Gambar 5. Dalam gambar tersebut terlihat 27 siswa dari 32 siswa dinyatakan tuntas dalam Deskripsi Batuan Sedimen. Siklus 1 ini termasuk berhasil, karena 84,375\% siswa mendapat nilai di atas KKM. Ini di atas ketentuan yang ditetapkan, yang berpatokan pada angka $75 \%$ siswa tuntas KKM. Data tersebut mengandung arti bahwa Field study terintegrasi Hybrid
Learning berpotensi digunakan dalam pembelajaran Dasar-dasar Geologi.

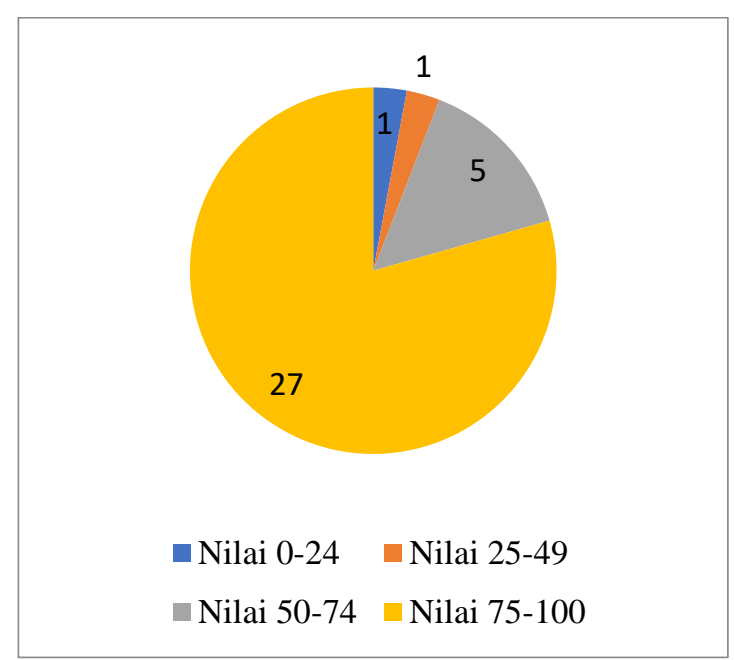

\section{Gambar 5. Diagram Nilai Yang Diperoleh Saat Siklus I}

\section{Refleksi}

Refeksi kali ini dilakukan melalui sintesis dan analisis temuan dari tiga tahap sebelumnya. Keberhasilan yang didapat dikarenakan beberapa faktor, antara lain materi batuan yang memang cocok dengan blended dan Field study. Seperti halnya geografi yang memiliki peluang besar untuk berhasil dengan penggunaan Hybrid Learning (Dikmenli, 2013; Godlewska et al., 2019; McPhee \& Pickren, 2017; Mitchell \& Forer, 2010; Moore \& Gilmartin, 2010). Geologi pun juga memiliki keberhasilan, ini karena geologi memiliki kemiripan dengan geografi (Stokes et al., 2011). Sesama ilmu kebumian kedua cabang ilmu ini dapat dipelajari secara Hybrid Learning.

Fiedlwork memberi pengalaman siswa belajar secara hands-on. Geologi merupakan ilmu yang cocok dipelajari secara Fieldstudy, karena ini memang ciri khasnya (Stokes et al., 2011). Dengan melakukan Field study siswa dapat melakukan deskripsi batuan dengan lebih baik dibandingkan hanya belajar secara online, sesuai dengan yang disampaikan 
(France \& Haigh, 2018). Field study dapat menjembatani teori dan kenyataan di alam, sedangkan belajar geologi secara online saja tidak bisa melakukan hal tersebut. Temuan ini juga mengonfirmasi pernyataan (Barros et al., 2012) bahwa Field study merupakan sumber pengetahuan yang baik bagi siswa yang belajar geologi.

\section{Siklus II}

\section{Perencanaan}

Tahap pertama yang dilakuakn saat Siklus II ini tidak memiliki banyak perbedaan dari perencanaan pada Siklus sebelumnya. Hal ini dilakukan karena melihat keberhasilan Siklus I. Siklus II ini hanya berusaha untuk menguatkan pendapat mengenai kemampuan Field study terintegrasi Hybrid Learning dalam pembelajaran Dasar-Dasar Geologi. Hal mendasar yang diganti ialah penentuan lokasi Field study, karena lokasi singkapan batuan sedimen (pada Siklus I) tidak sama dengan lokasi singkapan batuan metamorf (pada Siklus II). Penjadwalan pun dilakukan lebih lama dengan mempertimbangkan berbagai kondisi, salah satunya jumlah lokasi yang memiliki singkapan batuan metamorf tidak sebanyak lokasi singkapan batuan sedimen.

\section{Tindakan}

Tahap kedua siklus II berupa tindakan (treatment) juga tidak banyak mengalami perubahan. Siswa tetap harus melakukan Field study dengan tahap saintifik. Siswa juga harus mengirimkan foto atau video saat sedang di lapangan, saat mengambil sampel batuan, dan saat mendeskripsikan batuan. Format lembar deskripsi batuan metamorf dan sedimen memang berbeda, namun guru sudah mengirim materi berupa PDF di dalam
Google Classroom, sehingga siswa dapat mempelajarinya.

\section{Observasi}

Siswa masih ada yang tidak menggunakan APD saat ke lapangan. Ini sebenarnya kesalahan yang fatal dalam pelaksanan belajar geologi di lapangan. Tidak menggunakan APD berarti siswa mengabaikan K3. Siswa juga masih ada yang tidak pakai masker. Kedua hal ini menjadi perhatian serius dari guru. Teguran terhadap siswa yang mangabaikan APD dan masker tetap dilakukan oleh guru. Hal ini dilakukan karena penelitian fokus pada pengaplikasian Field study terintegrasi Hybrid Learning. Jadi keselamatan siswa saat melaksanakan Field study juga menjadi perhatian guru.

Lokasi singkapan batuan metamorf jauh dari perkampungan dan sebagian tidak ada sinyal internet. Hal ini yang mengakibatkan komunikasi guru dan siswa jadi terkendala. Siswa yang harusnya melakukan deskripsi batuan metamorf, malah seperti melakukan deskripsi batuan sedimen. Namun, hal ini dapat dikoreksi saat siswa sudah sampai di rumah dan sudah ada sinyal komunikasi, sehingga masalah ini untuk sementara dapat teratasi.

Terdapat 11 siswa dinyatakan tidak tuntas KKM karena tidak melakukan Fieldstudy ke lapangan. Siswa beralasan lokasi singkapan batuan metamorf jauh dari rumah mereka dan tidak di izinkan orang tua untuk ke sana. Hal semacam ini yang belum guru antisipasi dalam perencanaan pembelajaran Field study terintegrasi Hybrid Learning. Namun 21 siswa lainnya $(77,78 \%)$ melaksanakan Field study dengan baik, meskipun saat di lapangan ada kendala sinyal komunikasi (Gambar 6). 




Gambar 6. Diagram Nilai Yang Diperoleh Saat Siklus I

\section{Refleksi}

Sebagian siswa tuntas KKM saat Siklus II. Siswa yang belum sesuai dengan KKM dikarenakan mereka tidak melaksanakan Field study dengan alasan jauh dari rumah dan tidak mendapat izin orang tua. Guru perlu menggantinya dengan penugasan lain. Namun yang menjadi catatan di sini ialah bahwa penentuan lokasi Field study harus direncanakan secara matang, perlu menghubungi orang tua agar mendapatkan izin, dan perlu mengantisipasi hal-hal lain yang kemungkinan dapat menghambat Field study seperti susahnya sinyal komunikasi.

Persentase siswa yang tuntas KKM saat Siklus II meskipun tidak setinggi Siklus I menunjukkan keberhasilan yang sangat berarti. Hal ini ditunjukkan dengan lebih dari $75 \%$ siswa yang tuntas. Hal ini menunjukkan bahwa Field study terintegrasi Hybrid Learning efektif digunakan untuk pembelajaran Dasar Geologi di masa pandemi COVID19 (Gambar 7).

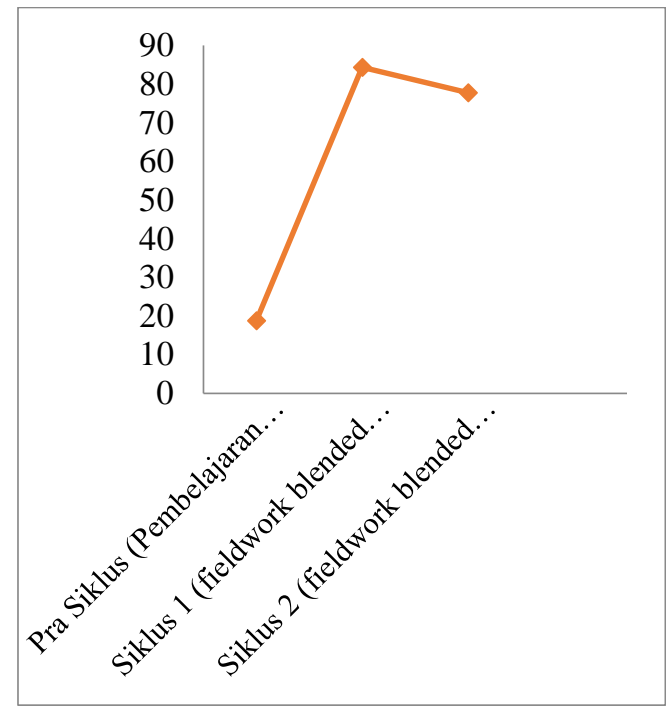

Gambar 7. Grafik Persentase Jumlah Siswa Tuntas KKM Saat Pra Siklus, Siklu I, dan Siklus II

Field study dengan menggunakan langkah-langkah pembelajaran saintifik mampu membekali siswa kemampuan memecahkan masalah, berpikir kritis, kerja sama tim dan kecerdasan emosional, juga karena Field study yang dilakukan dilaksanakan secara pendeketan saintifik sesuai saran dan mengunakan uji produk (Oktavianto et al., 2017). Field study memang sesuai dengan penilaian uji produk dibanding ujian tulis.

\section{KESIMPULAN}

Berdasarkan yang telah disampaikan pada hasil dan pembahasan di atas, ditarik kesimpulan bahwa integrasi Field study dengan Hybrid Learning efektif untuk menghadirkan pembelajaran berkualitas dilihat melalui jumlah siswa yang tuntas. Siklus I menunjukkan bahwa 84,374 \% siswa tuntas KKM, sedangkan pada Siklus II sebanyak $77,78 \%$ siswa tuntas KKM. Jumlah siswa yang tuntas KKM meskipun menurun dari Siklus I ke Siklus II tetapi tetap menunjukkan ketuntasan di atas $75 \%$ atau dikatakan berhasil. Hal ini juga 
menunjukkan bahwa Field study terintegrasi Hybrid Learning efektif digunakan dalam pembelajaran DasarDasar Geologi selama pandemi.

Field study terintegrasi Hybrid Learning dilaksanakan dengan meniadakan pembelajaran face-to-face. Siswa tetap diharuskan melaksanakan pembelajaran secara hands-on. Model ini juga disarankan menggunakan pendekatan saintifik. Selama pembelajaran Field study, sebisa mungkin guru berkomunikasi dengan siswa.

Saran bagi peneliti atau guru lain yang akan menggunakan Field study teringerasi Hybrid Learning ialah hendaknya memastikan bahwa lokasi Field study dapat dijangkau oleh siswa dan terdapat sinyal komunikasi serta internet. Guru dapat membimbing intensif jika sinyal komunikasi dan internet terdapat di lokasi Field study, dan ini merupakan hal yang sangat penting. Terkait masalah pandemi COVID-19, perlu menyusun panduan pembelajaran Field study terintegrasi Hybrid Learning secara cermat dan tepat sesuai protokol kesehatan, karena di penelitian ini masih ditemukan adanyan siswa yang mengabaikan penggunaan masker.

\section{DAFTAR PUSTAKA}

Bao, W. (2020). COVID -19 and online teaching in higher education: A case study of Peking University. Human Behavior and Emerging Technologies, 2(2), 113-115. https://doi.org/10.1002/hbe2.191

Barros, J. F. de, Almeida, P. A., \& Cruz, N. (2012). Fieldwork in Geology: Teachers' Conceptions and Practices. Procedia - Social and Behavioral Sciences, 47, 829-834. https://doi.org/10.1016/j.sbspro.20 12.06.743

Basilaia, G., \& Kvavadze, D. (2020). Transition to Online Education in Schools during a SARS-CoV-2 Coronavirus (COVID-19) Pandemic in Georgia. Pedagogical Research, 5(4). https://doi.org/10.29333/pr/7937

Clark, I., \& James, P. (2012). Blending what? An approach to delivering earth science courses online. International Journal of Innovation in Science and Mathematics Education (Formerly CAL-Laborate International), 14(1).

Dikmenli, Y. (2013). Effect of the blended learning environment and the application of virtual Ülkü Eser Ünaldi. Mevlana International Journal of Education (MIJE), 3(2), 43-56.

France, D., \& Haigh, M. (2018). Fieldwork@40: Fieldwork in geography higher education. Journal of Geography in Higher Education, 42(4), 498-514. https://doi.org/10.1080/03098265. 2018.1515187

Godlewska, A., Beyer, W., Whetstone, S., Schaefli, L., Rose, J., Talan, B., Kamin-Patterson, S., Lamb, C., \& Forcione, M. (2019). Converting a large lecture class to an active blended learning class: Why, how, and what we learned. Journal of Geography in Higher Education, 43(1), 96-115. https://doi.org/10.1080/03098265. 2019.1570090

Hung, M. L., Chou, C., Chen, C. H., \& Own, Z. Y. (2010). Learner readiness for online learning: Scale development and student perceptions. Computers and Education, 55(3), 1080-1090. 
https://doi.org/10.1016/j.compedu. 2010.05.004

Liu, X., Liu, S., Lee, S.-H., \& Magjuka, R. J. (2010). International Forum of Educational Technology \& Society Cultural Differences in Online Learning: International Student Perceptions. Source: Journal of Educational Technology \& Society, 13(3), 177188.

https://doi.org/10.2307/jeductechs oci.13.3.177

McPhee, S., \& Pickren, G. (2017). Blended learning with international students: $\quad A$ multiliteracies approach. Journal of Geography in Higher Education, 41(3), 418-433. https://doi.org/10.1080/03098265. 2017.1331208

Mitchell, P., \& Forer, P. (2010). Blended learning: The perceptions of firstyear geography students. Journal of Geography in Higher Education, 34(1), 77-89. https://doi.org/10.1080/030982609 02982484

Moore, N., \& Gilmartin, M. (2010). Teaching for better learning: A blended learning pilot project with first-year geography undergraduates. Journal of Geography in Higher Education, 34(3), 327-344. https://doi.org/10.1080/03098265. 2010.501552

Oktavianto, D. A. (2019a). Groups Investigation Learning Model to Analyze the Landscape Effect of Geological Processes Using Google Earth. Teknologi Pendidikan, 23(1), 1-14.

Oktavianto, D. A. (2019b). Pembuatan Model Pembelajaran Google Earth Untuk Meningkatkan Hasil Belajar Pemetaan Geologi.
Oktavianto, D. A., Sumarmi, \& Handoyo, B. (2017). Pengaruh Pembelajaran Berbasis Proyek Berbantuan Google Earth terhadap Keterampilan Berpikir Kritis the Effect of Project-Based Learning Assisted Google Earth to Spatial Thinking Skills. Jurnal Teknodik, 21(1), 1-15.

Pringle, J., Gardiner, A., \& Westerman, R. (2004). Virtual geological outcrops-Fieldwork and analysis made less exhaustive? Geology Today, 20(2), 67-71. https://doi.org/10.1111/j.13652451.2004.00450.x

Sahin, M. (2010). Blended learning in vocational education: An experimental study. International Journal of Vocational and Technical Education, 2(October), 95-101.

Samson, P. J., \& Samson, P. J. (2020). Student behaviors in a blended synchronous course Student behaviors in a blended synchronous course. Journal of Geoscience Education, 0(0), 1-10. https://doi.org/10.1080/10899995. 2020.1768002

Schifman, L., Cardace, D., Kortz, K., Saul, K., Gilfert, A., Veeger, A. I., \& Murray, D. P. (2013). Sleuthing through the rock cycle: An online guided inquiry tool for middle and high school geoscience education. Journal of Geoscience Education, 61(3), 268-279. https://doi.org/10.5408/12-326.1

Sintema, E. J. (2020). Effect of COVID-19 on the Performance of Grade 12 Students: Implications for STEM Education. Eurasia Journal of Mathematics, Science and Technology Education, 16(7), 1-6. https://doi.org/10.29333/ejmste/78 93 
Stokes, A., Magnier, K., \& Weaver, R. (2011). What is the use of fieldwork? Conceptions of students and staff in geography and geology. Journal of Geography in Higher Education, 35(1), 121-141. https://doi.org/10.1080/03098265. 2010.487203

Todhunter, B. (2013). LOL - limitations of online learning-Are we selling the open and distance education message short? Distance Education, 34(2), 232-252. https://doi.org/10.1080/01587919. 2013.802402

Viner, R. M., Russell, S. J., Croker, H., Packer, J., Ward, J., Stansfield, C., Mytton, O., Bonell, C., \& Booy, R. (2020). School closure and management practices during coronavirus outbreaks including COVID-19: A rapid systematic review. The Lancet Child and Adolescent Health, 4(5), 397-404. https://doi.org/10.1016/S23524642(20)30095-X

Wang, C. H., Shannon, D. M., \& Ross, M. E. (2013). Students' characteristics, self-regulated learning, technology self-efficacy, and course outcomes in online learning. Distance Education, 34(3), 302-323. https://doi.org/10.1080/01587919. 2013.835779

Zhang, W., Wang, Y., Yang, L., \& Wang, C. (2020). Suspending Classes Without Stopping Learning: China's Education Emergency Management Policy in the COVID-19 Outbreak. Journal of Risk and Financial Management, 13(3), 55. https://doi.org/10.3390/jrfm13030 055 